\title{
Bcl-2 inhibits Bax translocation from cytosol to mitochondria during drug-induced apoptosis of human tumor cells
}

\author{
KM Murphy', V Ranganathan ${ }^{2}$, ML Farnsworth ${ }^{3}$, \\ M Kavallaris ${ }^{3}$ and RB Lock ${ }^{\star, 3}$ \\ ${ }^{1}$ Department of Microbiology and Immunology, University of Louisville, \\ Louisville, Kentucky, KY 40202, USA \\ 2 The J. Graham Brown Cancer Center, University of Louisville, Louisville, \\ Kentucky, KY 40202, USA \\ ${ }^{3}$ Children's Cancer Institute Australia for Medical Research, High Street, \\ Randwick, NSW 2031, Australia \\ * Corresponding author: Richard B Lock, Children's Cancer Institute Australia \\ for Medical Research, High Street (PO Box 81), Randwick, NSW 2031, \\ Australia. Tel: +61 (2) 9382-1822; Fax: +61 (2) 9382-1850; \\ E-mail: Richard.Lock@unsw.edu.au
}

Received 26.4.99; revised 20.8.99; accepted 2.9.99

Edited by SJ Korsmeyer

\begin{abstract}
The pro-apoptotic protein, Bax, has been reported to translocate from cytosol to mitochondria following exposure of cells to apoptotic stresses including cytokine withdrawal and treatment with glucocorticoids and cytotoxic drugs. These observations, coupled with reports showing that Bax causes the release of mitochondrial cytochrome $c$, implicate Bax as a central mediator of the apoptotic process. In this report we demonstrate by subcellular fractionation a significant shift in Bax localization from cytosol to cellular membranes in two human tumor cell lines exposed to staurosporine or etoposide. Immunofluorescence studies confirmed that Bax specifically relocalized to the mitochondria. This redistribution of Bax occurred in concert with, or just prior to, proteolytic processing of procaspase-3, activation of DEVD-specific cleavage activity and degradation of poly(ADPribose) polymerase. However, Bax membrane translocation was independent of caspase activity as determined using the broad-range caspase inhibitor z-VAD-fmk. High level overexpression of the anti-apoptotic protein $\mathrm{Bcl}-2$ prevented $\mathrm{Bax}$ redistribution to the mitochondria, caspase activation and apoptosis following exposure to staurosporine or etoposide. These data confirm the role of Bax in mitochondrial cytochrome $c$ release, and indicate that prevention of Bax translocation to the mitochondrial membrane represents a novel mechanism by which Bcl-2 inhibits drug-induced apoptosis. Cell Death and Differentiation (2000) 7, 102-111.
\end{abstract}

Keywords: apoptosis; Bax; etoposide; staurosporine

Abbreviations: caspases, cysteine-dependent aspartate-specific proteases; BSA, bovine serum albumin; CHAPS, 3-[(3-cholamido- propyl)dimethylammonio]-1-propanesulfonic acid; Ac-DEVD-pNA, acetyl-L-aspartyl-L-glutamyl-L-valyl-L-aspart-1-p-nitroanilide; COX, cytochrome oxidase subunit VIc; HEPES, (N-[2-hydroxyethyl]piperazine- $\mathrm{N}^{\prime}$-[2-ethanesulfonic acid]); HeLa, human cervical carcinoma cell line; PBS, calcium- and magnesium-free phosphate-buffered saline; PIPES, 1,4-piperazinediethanesulfonic acid; STP, staurosporine; PARP, poly(ADP-ribose) polymerase; topo I, DNA topoisomerase I; z-VAD-fmk, carbobenzoxy-L-valyl-Lalanyl- $\beta$-methyl-L-aspart-1-yl-fluoromethane

\section{Introduction}

Apoptosis (programmed cell death) is critical for the normal development and homeostatic maintenance of multicellular organisms, and its deregulation has been associated with autoimmune disease, neurodegenerative disorders, and malignancy. ${ }^{1}$ Apoptosis can be triggered by various stimuli, including withdrawal of growth factors, application of chemotherapeutic drugs, and crosslinking of death signal transmitting receptors. ${ }^{1,2}$ Once initiated the characteristics of apoptotic death include membrane blebbing, cell shrinkage, chromatin condensation, DNA fragmentation and the formation of plasma membrane-bound apoptotic bodies. ${ }^{3}$

The initiation and execution phases of apoptosis are controlled by a sequential cascade of activation, by proteolytic cleavage, of a family of cysteine-dependent, aspartate-specific proteases (caspases). ${ }^{4}$ Different members of the caspase family exhibit variations in substrate sequence specificity $\mathrm{N}$-terminal to the required aspartate residue. ${ }^{4,5}$ For example, caspase-3 (also known as CPP32/ YAMA/apopain) preferentially cleaves on the carboxyl side of the tetrapeptide sequence Asp-Glu-Val-Asp (DEVD), a sequence present in poly(ADP-ribose) polymerase (PARP). ${ }^{4,6}$ Indeed, cleavage of PARP is considered an early marker for chemotherapeutic drug-induced apoptosis. $^{4,7,8}$ Additional proteins that serve as targets for the caspase family include nuclear lamins, DNA-activated protein kinase, actin, $\mathrm{U} 1-70 \mathrm{kDa}$ protein, and protein kinase $\mathrm{C} \delta .4,9$ Cleavage and activation of procaspase-3, which may serve as a convergence point for differing apoptotic stimuli, ${ }^{4,9,10}$ is catalyzed by caspase- 9 both in vitro $^{11}$ and in vivo. ${ }^{12,13}$ Activation of procaspase-9 is controlled by a complex of Apaf-1 (the human homologue of the $C$. elegans CED-4 protein), cytochrome $c$ and dATP. ${ }^{11}$

The cellular commitment to apoptosis is regulated by the $\mathrm{Bcl}-2$ family of proteins, which includes the death agonists $\mathrm{Bax}$, Bak, Bad and $\mathrm{Bcl}-\mathrm{x}_{\mathrm{S}}$, and antagonists $\mathrm{Bcl}-2, \mathrm{Bcl}-\mathrm{w}$, $\mathrm{Mcl}-1$ and $\mathrm{Bcl}-\mathrm{x}_{\mathrm{L}}{ }^{14-16}$ While homo- and hetero-dimeric interactions have been shown to play a significant role in the function of these proteins, members of the Bcl-2 family 
also act by independent mechanisms. ${ }^{7,14-17}$ Mitochondrial dysfunction occupies a central role in the induction of apoptosis via release of cytochrome $c$ and other apoptosisinducing factors. This process involves disruption of the mitochondrial inner transmembrane potential $\left(\Delta \Psi_{\mathrm{m}}\right)$ due to opening of the mitochondrial permeability transition pore. ${ }^{14,15,18}$ Anti-apoptotic proteins such as Bcl-2 and Bcl$X_{L}$ inhibit the mitochondrial permeability transition and cytochrome $c$ release, ${ }^{19-21}$ although effects downstream of cytochrome $c$ release have been documented. ${ }^{22,23}$

Recent data indicate that Bax is a monomeric and predominantly cytosolic protein in non-stressed cells. ${ }^{24-27}$ This distribution contrasts to the restricted localization of Bcl-2 to cellular membrane compartments, including the endoplasmic reticulum, outer mitochondrial membrane, and nuclear envelope. ${ }^{24,26,28}$ Bax has been shown to translocate to mitochondria and undergo conformational changes in mammalian cells upon cytokine withdrawal, exposure to glucocorticoids or treatment with the protein kinase inhibitor staurosporine (STP). ${ }^{24-27}$ Deletion of the C-terminal hydrophobic domain of Bax inhibits its ability to insert into the mitochondrial membrane and induce cell death, ${ }^{26}$ whereas enforced dimerization of Bax causes its translocation to mitochondria and ensuing cell death. ${ }^{24}$ Furthermore, recombinant Bax has been shown to cause cytochrome $c$ release from mitochondria in vitro ${ }^{29}$ and in intact cells. ${ }^{23}$

Previous reports of specific Bax localization to mitochondria have utilized model systems of high level ectopic Bax expression. $^{23,26}$ In this report we investigate the relationships between mitochondrial translocation of endogenous Bax, caspase activation and PARP cleavage in human tumor cells exposed to STP or etoposide. Our results support a model in which Bax insertion into the mitochondrial membrane causes release of cytochrome $c$ resulting in activation of caspases and cellular apoptosis. Furthermore, we demonstrate that Bax translocation to mitochondria is independent of caspase activity but inhibited by $\mathrm{Bcl}-2$ overexpression, suggesting that $\mathrm{Bcl}-2$ either occupies the Bax membrane insertion site or controls an upstream event necessary for Bax insertion.

\section{Results}

STP-induced Bax translocation from the cytosol to the membrane fraction is independent of caspase activity

Bax translocation from cytosol to mitochondria has been observed in mammalian cell lines exposed to various apoptotic stimuli, ${ }^{24,26,27}$ including HL-60 cells treated with STP. ${ }^{27}$ In order to relate these previous studies to our experimental models, HL-60 cells were exposed to STP and subcellular fractions prepared following freeze/thaw lysis in hypotonic buffer. Figure $1 \mathrm{~A}$ demonstrates that almost all detectable Bax (cytosolic) and Bcl-2 (membrane) localized to separate subcellular compartments in unstressed cells, in agreement with previous studies. ${ }^{27}$ However, within $2 \mathrm{~h}$ of STP treatment a significant proportion of Bax had shifted to the membrane fraction and by $8 \mathrm{~h}$ almost $100 \%$ of Bax had translocated (Figure 1A,B). Redistribution of Bax was accompanied by disappearance of procaspase-3 (Figure $1 \mathrm{~A})$, as well as activation of DEVD-specific cleavage activity (Figure 1B). In HL-60 cells, and the results using HeLa cells described below, procaspase-3 was detected exclusively in the cytosolic fraction. Decreased $\mathrm{Bcl}-2$ and actin signals in $\mathrm{HL}-60$ cells were detected at $8 \mathrm{~h}$ compared to earlier timepoints, possibly due to proteolytic degradation, at which time loss of plasma membrane integrity became apparent (Figure 1A). Thus, STP-induced Bax membrane translocation is accompanied by activation of caspase-3, both of which occur prior to loss of plasma membrane integrity.

In order to establish whether the relocalization of Bax from the cytosol to the membrane fraction in response to an apoptotic stimulus was dependent on caspase activation, HL-60 cells were incubated with the broad-range caspase inhibitor, z-VAD-fmk, for $4 \mathrm{~h}$ prior to and during STP treatment. Figure 2A shows that z-VAD-fmk had no effect on STP-induced Bax membrane translocation. In contrast, z-VAD-fmk completely inhibited STP-induced DEVD-cleavage activity (Figure $2 B$ ). z-VAD-fmk treatment alone had

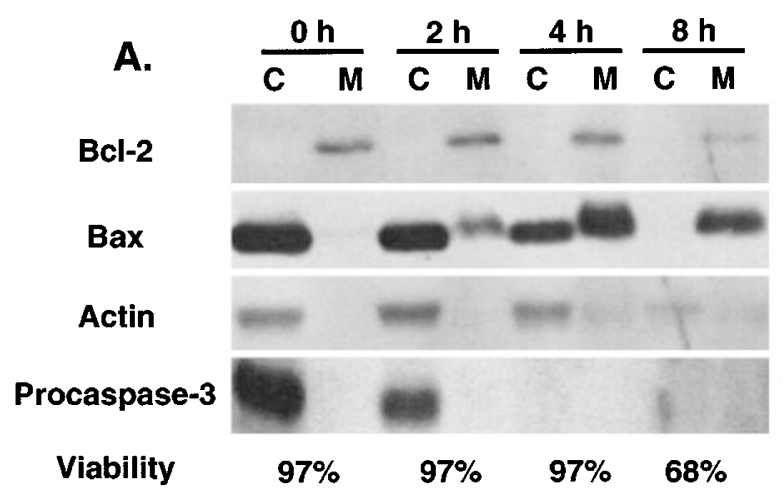

B.

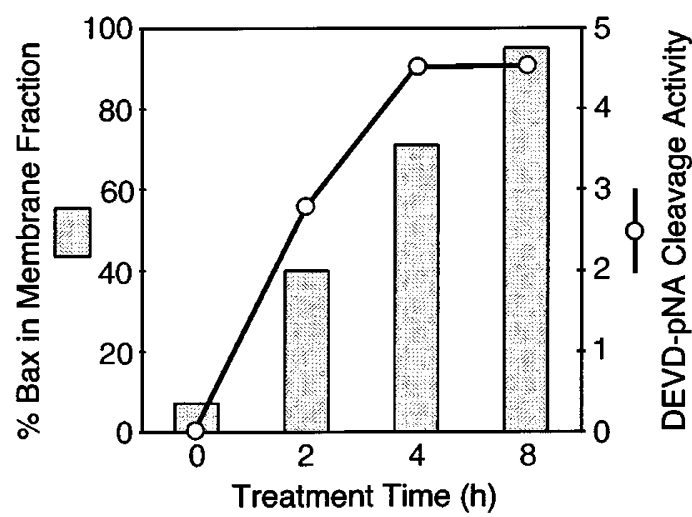

Figure 1 Bax subcellular redistribution, procaspase-3 processing and activation of DEVD-specific cleavage activity in HL-60 cells exposed to STP. HL-60 cells were treated with $1 \mu \mathrm{M}$ STP for $0,2,4$ or $8 \mathrm{~h}$, then harvested and processed for subcellular fractionation or caspase activity assays, as described in the text. (A) Immunoblots which are representative of at least three separate experiments. $C$ and $M$ denote cytosolic and membrane fractions (including nuclear, heavy and light membranes), respectively. Viability was estimated by trypan blue exclusion. (B) The proportion of Bax in the membrane fraction and DEVD-specific cleavage activity. Each point represents the mean of two separate experiments 
no significant effect on Bax localization or DEVD-cleavage activity compared to solvent-treated controls (data not shown). Thus, STP-induced Bax membrane translocation is independent of caspase activity.

\section{Overexpression of $\mathrm{Bcl}-2$ prevents Bax membrane translocation in STP-treated HeLa cells}

In order to determine the effects of $\mathrm{Bcl}-2$ overexpression on Bax membrane translocation, we utilized HeLa cells that had been transfected with pSFFV-Bcl-2. ${ }^{30,31}$ Stable overexpression of $\mathrm{Bcl}-2$ in these cells (clone B-5) has been shown to confer resistance to drug-induced apoptosis compared to cells transfected with empty vector alone (clone S-1). ${ }^{30,31}$ HeLa S-1 and B-5 cells were exposed either to STP or to etoposide and subcellular fractions prepared as described above for HL-60 cells. In non-treated S-1 and B- 5 cells $>80 \%$ of Bax was cytosolic while almost $100 \%$ of $\mathrm{Bcl}-2$ localized to membrane fractions in B-5 cells (Figures 3 and 5).

STP exposure resulted in a significant shift in the localization of Bax from cytosolic to membrane fractions in $S-1$ cells (Figure $3 A$, lanes $a-f$ ), similar to HL-60 cells (Figure 1). It should be noted that HeLa cells appeared less sensitive than HL-60 cells to STP, and a shift in Bax distribution was not observed prior to $16 \mathrm{~h}$ STP treatment of HeLa cells (data not shown). In HeLa S-1 cells exposed to STP the proportion of Bax in the membrane fraction increased between $16 \mathrm{~h}$ and $24 \mathrm{~h}(\sim 45 \%$ at $16 \mathrm{~h}$ and $>65 \%$ at $24 \mathrm{~h}$, Figure $3 \mathrm{~A}$ ). This redistribution of Bax
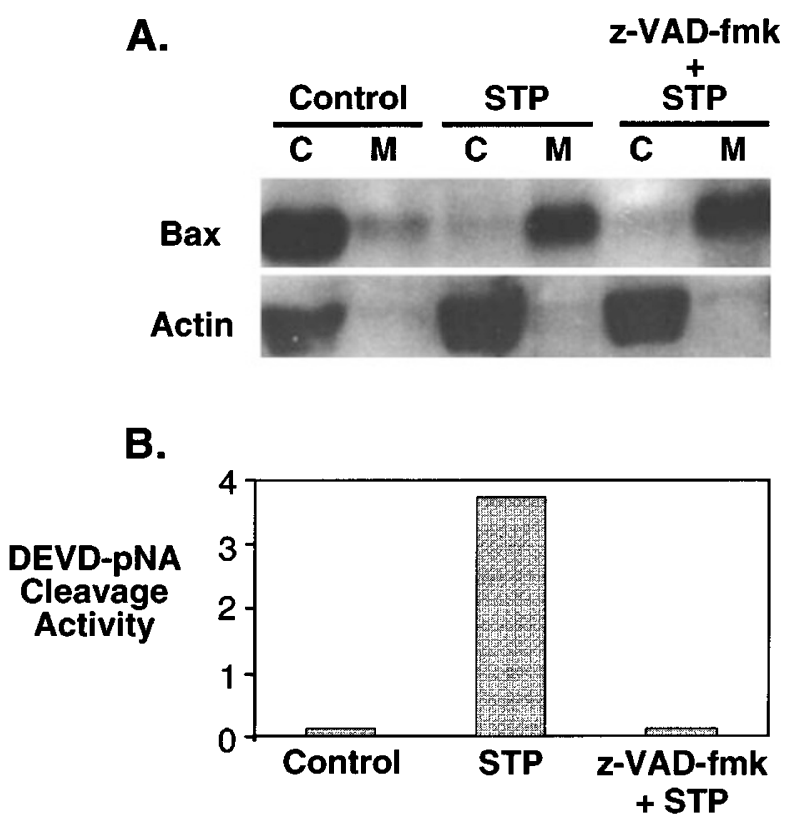

Figure 2 STP-induced Bax relocalization is independent of caspase activity. HL-60 cells were incubated with $75 \mu \mathrm{M}$ z-VAD-fmk for $4 \mathrm{~h}$ prior to and during STP exposure ( $1 \mu \mathrm{M}, 6 \mathrm{~h})$, following which cells were harvested and processed for subcellular fractionation and immunoblotting (A) or DEVD-specific cleavage activity assays (B), as described in the text. $C$ and $M$ denote cytosolic and membrane fractions (including nuclear, heavy and light membranes), respectively. Control, represents a solvent-treated control population. Data shown are from a single experiment was accompanied by degradation of PARP (detected almost exclusively in the membrane fractions of $\mathrm{HeLa}$ cells, Figure $3 A$, lanes $a-c)$, a reduction in procaspase-3 (Figure 3A, lanes $d-f$ ), and increased DEVD-specific cleavage activity (Figure $3 \mathrm{~B}$ ). The distribution of marker proteins remained unaltered, including topo I (nuclear), actin (predominantly cytosolic) and COX (mitochondrial, Figure $3 A$, lanes $a-f)$. In contrast, no significant shift in Bax subcellular distribution was observed in STP-treated B-5 cells (Figure $3 \mathrm{~A}$, lanes $\mathrm{g}-\mathrm{i}$ ). Consistent with the ability of overexpressed $\mathrm{Bcl}-2$ to inhibit STP-induced apoptosis in these cells, both PARP (Figure 3A, lanes $\mathrm{g}-\mathrm{i}$ ) and procaspase (Figure $3 A$, lanes $\mathrm{j}-\mathrm{I}$ ) remained intact, while activation of DEVD-specific cleavage was suppressed (Figure 3B). Thus, overexpression of $\mathrm{Bcl}-2$ not only resulted in the inhibition of characteristic apoptotic events induced by STP, it also prevented redistribution of Bax from cytosol to cellular membrane fractions.

\section{Bax specifically relocalizes to mitochondria with concomitant release of cytochrome $c$ during drug-induced apoptosis}

Immunofluorescence staining with confocal microscopy was utilized to identify the precise subcellular location of Bax translocation. Bax gave a coarse staining pattern in untreated cells (Figure 4A,E), which did not co-localize with mitochondria as determined using MitoTracker Red (Figure 4C) and cytochrome $c$ staining (Figure 4G,I). However, STP treatment resulted in a punctate Bax staining pattern (Figure $4 \mathrm{~B}, \mathrm{~F}$ ) with evidence of mitochondrial clustering due to its co-localization with MitoTracker Red (Figure 4D). The remainder of the green staining in Figure 4D is consistent with the approximate $55 \%$ of Bax remaining in the cytosolic fraction at this timepoint (Figure 3A, lanes b,e). The mitochondrial clustering of Bax was associated with an alteration in the cytochrome $c$ staining pattern from mitochondrial to a more diffuse cytosolic distribution (Figure $4 \mathrm{H}, \mathrm{J}$ ), indicating release of cytochrome $c$ from the mitochondria.

Throughout the course of these experiments, punctate Bax staining always accompanied a diffuse cytochrome $c$ cellular staining pattern (data not shown). This suggests that $\mathrm{Bax}$ relocalization to the mitochondria precedes cytochrome $c$ release. The staining pattern of Bax in B-5 cells remained unaltered following STP treatment (data not shown). Thus, Bax membrane translocation is specific to mitochondria, is associated with mitochondrial release of cytochrome $c$ and, consistent with the immunoblot data, is blocked by $\mathrm{Bcl}-2$ overexpression.

\section{Bax membrane translocation occurs during etoposide-induced apoptosis and is inhibited by $\mathrm{Bcl}-2$ overexpression}

In order to determine whether Bax membrane insertion was a common manifestation of cytotoxic drug action, S- 1 and B-5 cells were exposed to the DNA damaging event and cancer chemotherapeutic compound etoposide. Similar to STP, etoposide treatment of $\mathrm{S}-1$ cells resulted in a time-dependent 
increase in the amount of Bax that localized to the cellular membrane fraction (Figure 5, lanes $a-e$ ). The redistribution of Bax was accompanied by PARP degradation (Figure 5, lanes $a-e)$, while the Coomassie blue gel staining pattern remained unaltered (Figure 5, lower panel). In a single experiment, over $85 \%$ of Bax had relocalized to the membrane fraction at $72 \mathrm{~h}$ following etoposide removal (data not shown). Figure 5 also demonstrates that $\mathrm{Bcl}-2$ overexpression in $\mathrm{B}-5$ cells

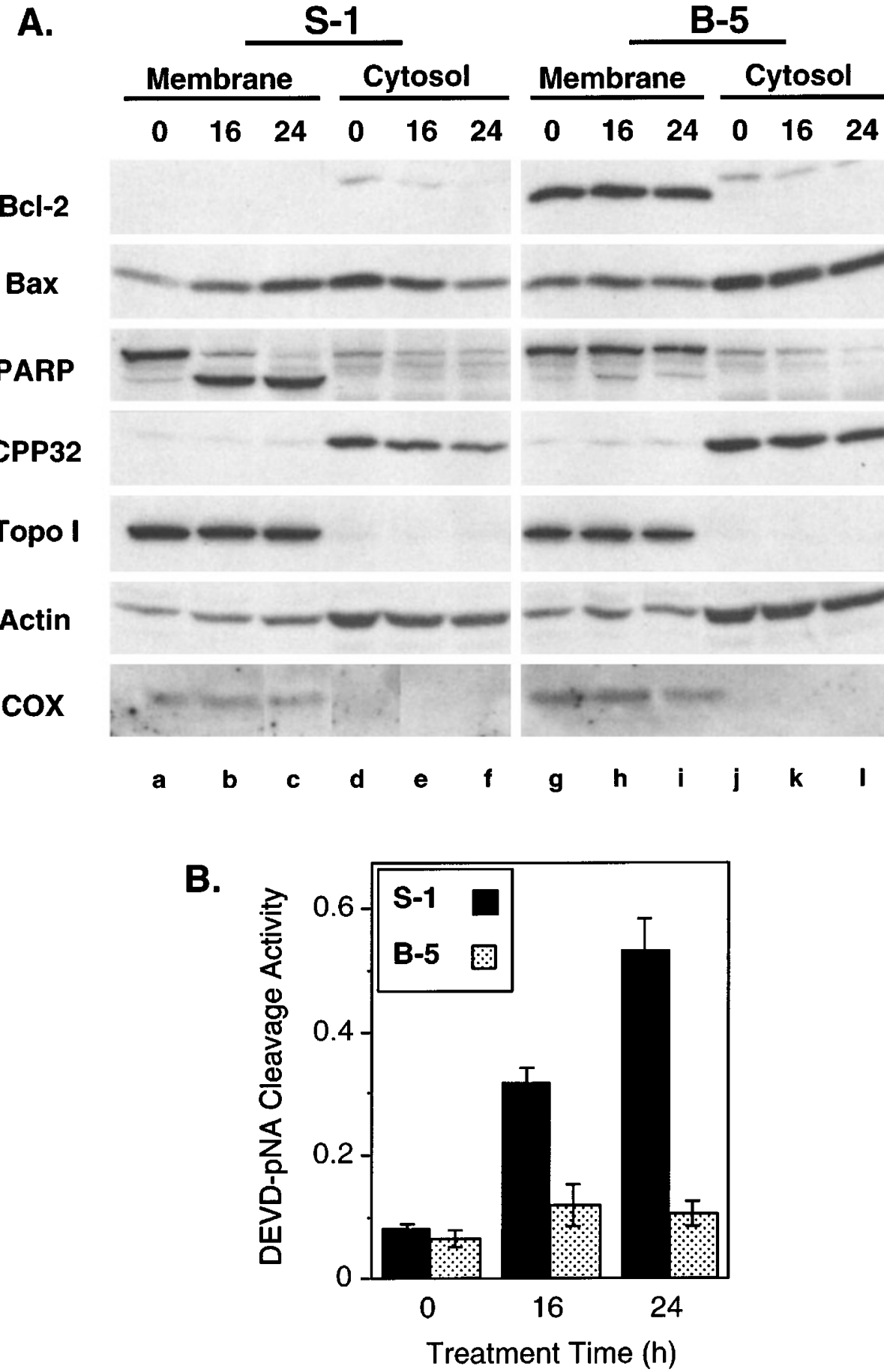

Figure 3 Inhibition of Bax translocation, PARP cleavage, procaspase-3 processing and caspase activation by Bcl-2 in HeLa cells exposed to STP. HeLa S-1 or B5 cells were exposed to $1 \mu \mathrm{M} \mathrm{STP}$ for 0,16 or $24 \mathrm{~h}$, then harvested and processed for subcellular fractionation or caspase activity assays. (A) immunoblots which are representative of two separate experiments. The integer above each lane denotes the STP exposure time (h). Membrane (lanes a-c and g-i) and Cytosol (lanes $\mathrm{d}-\mathrm{f}$ and $\mathrm{j}-\mathrm{I}$ ) refer to the pellet and supernatant from a $100000 \times g$ centrifugation, respectively, following freeze-thaw lysis. The slower-migrating band in the $\mathrm{Bcl}-2$ immunoblots of cytosolic fractions (lanes $d-f$ and $j-I$ ) is non-specific binding (B) DEVD-specific cleavage activity in S-1 and B-5 cells. Data are the mean \pm S.D. of two separate experiments 
prevented etoposide-induced Bax membrane translocation and PARP degradation (Figure 5, lanes $\mathrm{k}-0$ ).

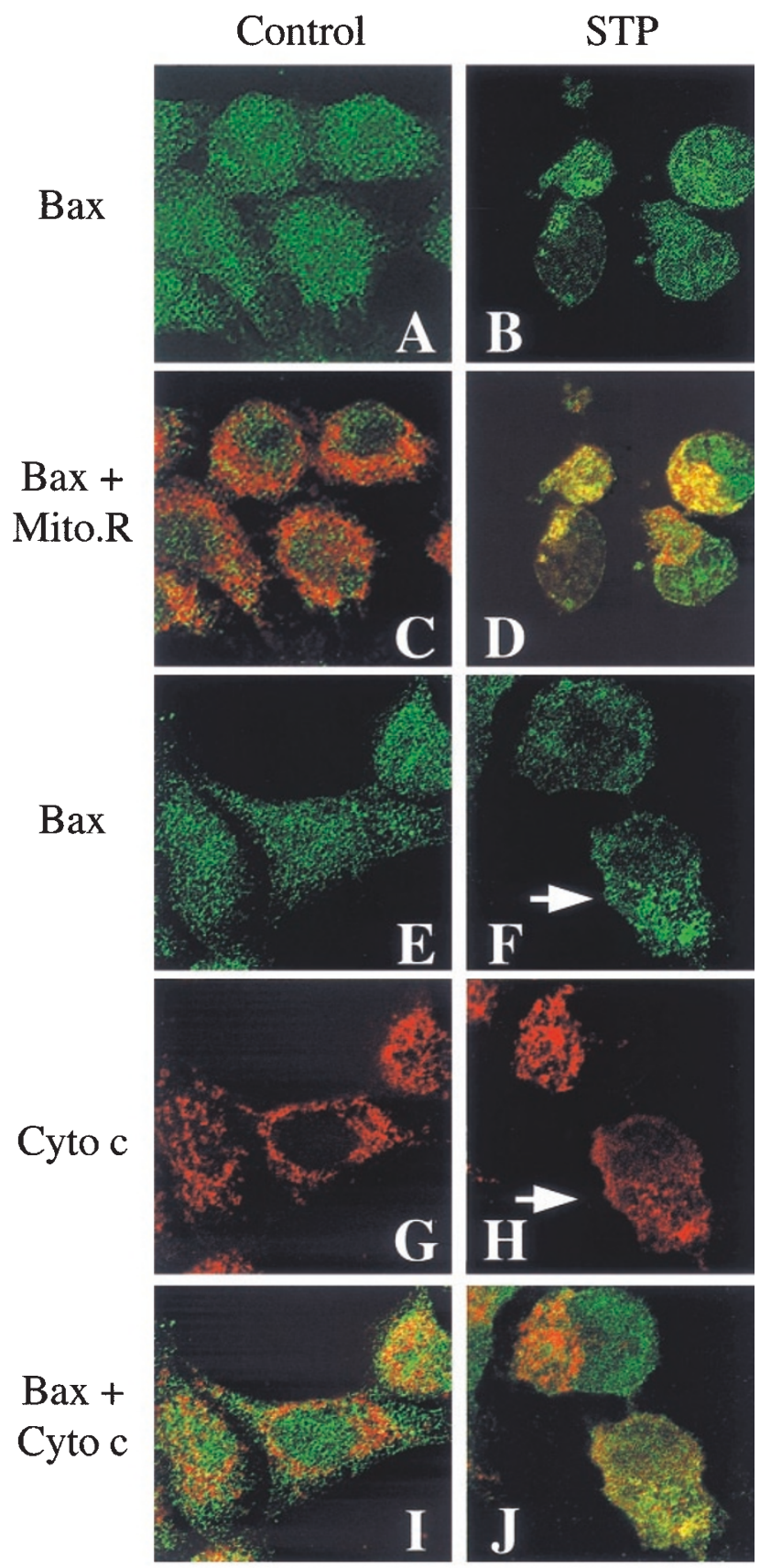

Figure 4 Immunofluorescence of Bax, MitoTracker Red (Mito.R) and cytochrome $c$ (Cyto $\mathrm{c}$ ) subcellular distribution during STP-induced apoptosis of HeLa cells. Cells were grown on coverslips, exposed to solvent control $(\mathbf{A}, \mathbf{C}, \mathbf{E}, \mathbf{G}, \mathbf{I})$ or $1 \mu \mathrm{M}$ STP $(\mathbf{B}, \mathbf{D}, \mathbf{F}, \mathbf{H}, \mathbf{J})$ for $16 \mathrm{~h}$, and stained with antibodies raised against Bax or cytochrome $c$ as described in the text. Bax staining is represented by green fluorescence, while MitoTracker Red and cytochrome $c$ are represented by red fluorescence. Subcellular distribution of Bax (A,B,E,F), Bax combined with MitoTracker Red (C,D), cytochrome $c(\mathbf{G}, \mathbf{H})$ or Bax and cytochrome $c$ simultaneously $(\mathbf{I}, \mathbf{J})$ was revealed by confocal microscopy. In $(\mathbf{F}, \mathrm{H})$, the cell exhibiting a punctate Bax and diffuse cytochrome $c$ staining pattern is indicated by an arrow. In $(\mathbf{C}, \mathbf{D}, \mathbf{I}, \mathbf{J})$, co-localization of green and red fluorescence is indicated by yellow coloration
The temporal relationships between etoposide-induced Bax membrane translocation, activation of DEVD-specific cleavage activity, PARP degradation and loss of plasma membrane integrity in S-1 and B-5 cells are shown in Figure 6 , representing the mean of four separate experiments. These data indicate that, in etoposideinduced apoptosis, Bax membrane translocation (Figure 6A) marginally precedes caspase activation (Figure 6B) and PARP cleavage (Figure 6C), all of which occur prior to loss of cell viability (Figure 6D). These results are consistent with those of Zhang et al. $^{32}$ who reported that STP-induced Bax redistribution precedes caspase-3 activation, indicating that redistribution of Bax is an early event in apoptosis. In addition, Figure 6 demonstrates that overexpression of $\mathrm{Bcl}-2$ inhibits all four of these processes.

\section{Discussion}

The data presented in this report contribute to our further understanding of the molecular ordering of cellular processes during drug-induced apoptosis. Relocalization of Bax from the cytosol to the mitochondria is an early, caspase-independent, event during STP- or etoposide-induced apoptosis, and occurs in close association with mitochondrial cytochrome $c$ release, activation of DEVD-specific cleavage activity, processing of procaspase-3, and cleavage of PARP. All of these events, including subsequent loss of plasma membrane integrity, are inhibited by overexpression of $\mathrm{Bcl}-2$ suggesting that translocation of Bax to the mitochondria occurs downstream of the point at which Bcl-2 exerts its anti-apoptotic effects.

In all cell lines we have examined (including HL-60, HeLa, MCF-7, MCF10A1 and CEM), we have observed endogenous Bax to be predominantly located in the cytosolic compartment, which is consistent with previous reports. ${ }^{24-27}$ However, Bax has also been reported to be located in the cytosol, but in peripheral association with intracellular membranes, including the mitochondria. ${ }^{33}$ Additionally, Desagher et al. ${ }^{34}$ recently reported that in cultured cells, Bax was distributed in both the mitochondria and cytosol, while in freshly dissected tissues Bax was predominantly cytosolic and hardly detectable in the mitochondria. These apparently conflicting results may be due to differences in cell lines, culture conditions, or may reflect differences in the methodology employed to determine Bax subcellular location. Further work is required to understand these discrepancies.

Our finding that $\mathrm{Bax}$ and $\mathrm{Bcl}-2$ are localized to separate subcellular compartments in two human tumor cell lines confirms earlier reports that challenge the ability of $\mathrm{Bax} / \mathrm{Bcl}-$ 2 to form heterodimers in non-stressed cells. ${ }^{24-27}$ Furthermore, ectopic expression of $\mathrm{Bcl}-2$ in HeLa cells caused no apparent redistribution of Bax, in agreement with a previous study, ${ }^{26}$ but in contrast to another. ${ }^{35}$ These differences may reflect anomalies due to protein overexpression. Certainly, however, in HL-60 cells, endogenous $\mathrm{Bcl}-2$ does not appear to sequester Bax to the membrane compartment.

We have demonstrated that endogenous Bax protein relocalizes from the cytosol, specifically to the mitochondria 


\section{S-1

$\frac{\text { Membrane }}{\text { C } 081624 \text { C } 081624} \frac{\text { Cytosol }}{\text { C } 08 \text { 8 } 81624 \text { C } 081624}$

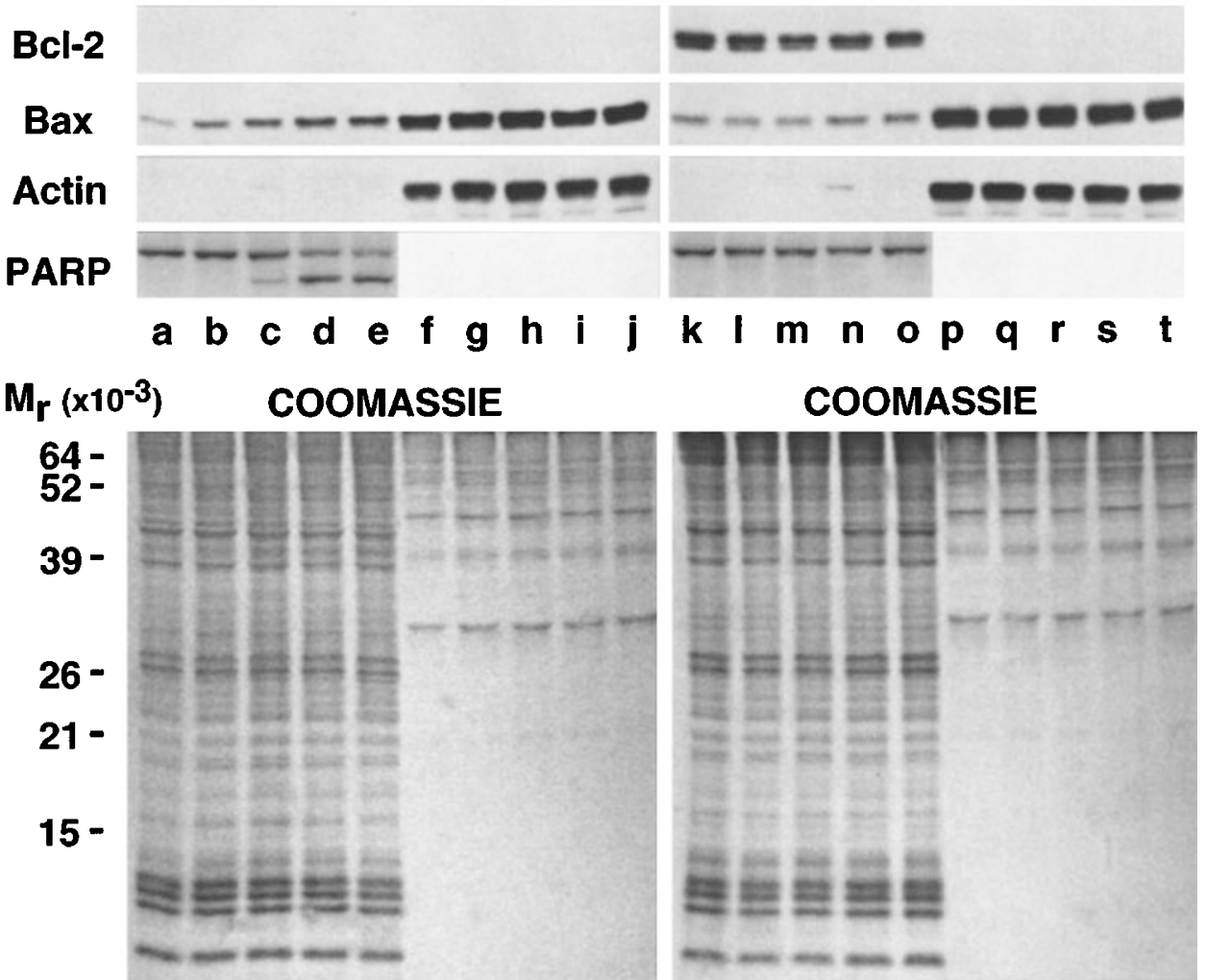

Figure 5 Bcl-2 inhibits Bax redistribution and PARP cleavage in HeLa cells exposed to etoposide. HeLa S-1 and B- 5 cells were exposed to etoposide ( $25 \mu \mathrm{M}, 4 \mathrm{~h})$ then incubated in drug-free medium for $0,8,16$ or $24 \mathrm{~h}$, and harvested as described for Figures $1-3$. Immunoblots are representative of four separate experiments. The integer above each lane denotes the number of hours following etoposide removal, while $C$ indicates the solvent-treated control lane. Membrane (lanes a- $\theta$ and $k-0$ ) and Cytosol (lanes $f-j$ and $p-t$ ) fractions were prepared as indicated in the legend to Figure 3 and in the text. A separate gel was run for the PARP immunoblot using only the membrane fractions from S-1 and B-5 cells. The lower panel shows a gel stained with Coomassie blue for verification of equal loading of each fraction, with the migration distance and $\mathrm{M}_{\mathrm{r}}$ of protein standards indicated

during apoptosis induced by chemotherapeutic drugs. Goping et al. ${ }^{33}$ demonstrated that IL-3 withdrawal resulted in Bax insertion into the mitochondrial membrane, as evidenced by an acquired resistance to alkaline extraction. In support of Bax translocation to the mitochondria being accompanied by membrane insertion, immunoprecipitation experiments suggest that Bax may directly interact with the adenine nucleotide translocator located in the inner mitochondrial membrane. ${ }^{36}$ The precise mechanism by which Bax relocates to the mitochondria following an apoptotic stimulus is presently unknown, but appears to involve conformational changes in its $\mathrm{N}$ - and $\mathrm{C}$-termini, resulting in exposure of the $\mathrm{C}$-terminal hydrophobic domain which functions as a signal-anchor sequence that is sufficient for mitochondrial targeting and membrane insertion. ${ }^{24,25,33,37}$ Deletion of the C-terminal hydrophobic domain inhibits its redistribution and death-promoting activity. ${ }^{26}$

Recombinant Bax has been shown to cause cytochrome $c$ release from mitochondria in vitro ${ }^{29}$ and in intact cells. ${ }^{23}$
On the contrary, it has also been reported that targeting of recombinant $\mathrm{Bax}$ to isolated mitochondria requires cytochrome $c^{33}$ In monitoring endogenous Bax localization during cytotoxic drug-induced apoptosis, cytochrome $c$ release was never observed in the absence of Bax translocation, supporting a model in which Bax translocation precedes cytochrome $c$ release. Cytochrome $c$ plays an active role in the apoptotic cascade by facilitating activation of downstream caspases through processing of procaspase-9. ${ }^{11}$ While it has been suggested that the primary site for $\mathrm{Bcl}-2$ regulation of apoptosis is by preventing cytochrome $c$ release, ${ }^{19,20}$ our results suggest that the mechanism by which $\mathrm{Bcl}-2$ blocks drug-induced apoptosis is by preventing Bax relocalization to the mitochondria. A similar observation has been reported previously in murine FL5.12 cells deprived of interleukin$3^{24}$

In addition to triggering cytochrome $c$ release, recombinant Bax, when microinjected into cells or added to isolated mitochondria, induces dissipation of mitochondrial $\Delta \Psi_{\mathrm{m}}$ and 


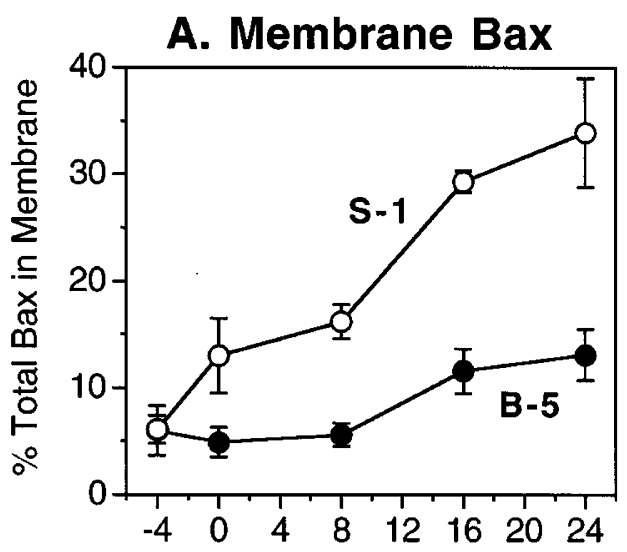

Post Treatment Incubation (h)

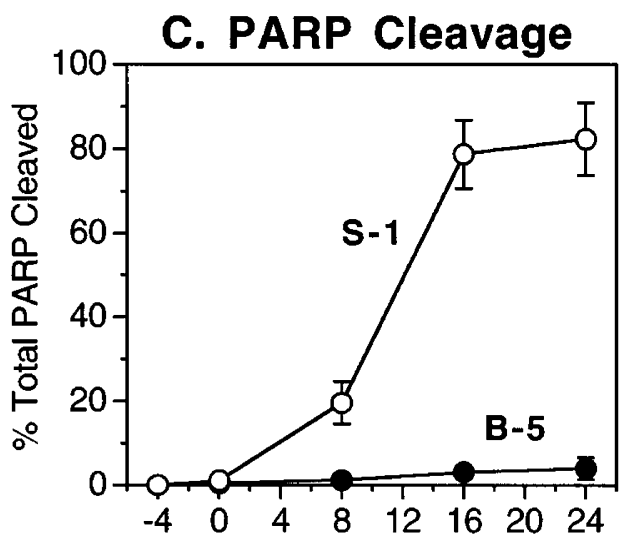

Post Treatment Incubation (h)

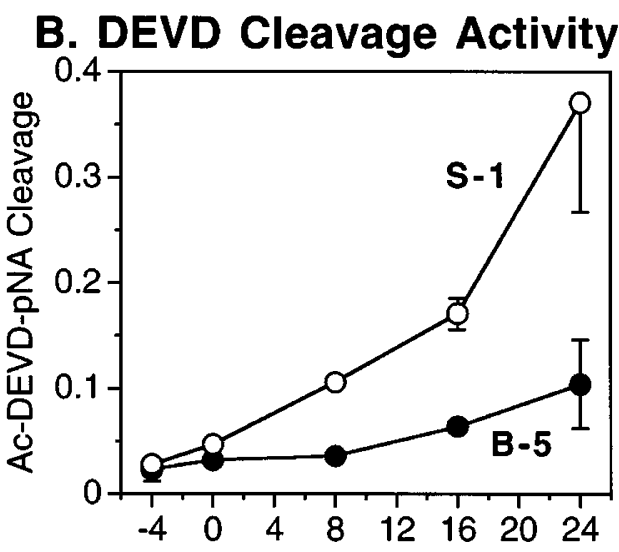

Post Treatment Incubation (h)

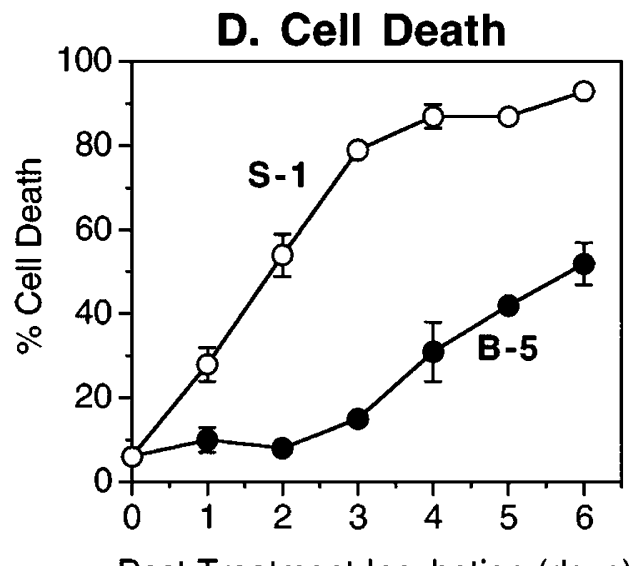

Post Treatment Incubation (days)

Figure 6 Inhibition of etoposide-induced Bax redistribution, activation of DEVD-specific cleavage activity, PARP cleavage and loss of plasma membrane integrity by Bcl-2 in HeLa cells. HeLa S-1 (open circles) and B-5 (filled circles) cells were treated, harvested and processed as described in the legend to Figure 5 . Each data point represents the mean \pm S.E. of four separate experiments

mitochondrial swelling. ${ }^{36}$ Therefore, it is possible that a cellular commitment to death results in Bax membrane insertion and subsequent death via apoptosis (following cytochrome $c$ release) or, in the absence of caspase activation, necrosis due to mitochondrial dysfunction and disruption of the electron transport chain. In support of this, it has been reported that Bax-induced cell death may not require caspase activity. ${ }^{38}$ Consistent with a previous report, we have demonstrated that STP-induced Bax redistribution is independent of caspase activity. ${ }^{32}$ However, Bax membrane translocation induced by Fas activation was caspase dependent, ${ }^{39}$ indicating a differential requirement of caspase activity for this process depending on the apoptotic stimulus.

The temporal and dependent relationship between cytochrome $c$ release and mitochondrial $\Delta \Psi_{\mathrm{m}}$ dissipation remains unclear at this time, however both are inhibited by $\mathrm{Bcl}-2$ (this study and reviewed in ${ }^{15}$ ). Bcl-2 and Bax both form distinct ion conductive channels in artificial lipid membranes, ${ }^{40}$ and $\mathrm{Bcl}-2$ appears to preferentially localize to the points of contact between the inner and outer mitochondrial membrane. ${ }^{15,16}$ Therefore, Bcl-2 may prevent dissipation of mitochondrial $\Delta \Psi_{\mathrm{m}}$ induced by Bax through mitochondrial megapore opening. Alternatively, because some studies have suggested that cytochrome $c$ release from mitochondria precedes loss of $\Delta \Psi_{\mathrm{m}},{ }^{20,41}$ it is possible that $\mathrm{Bcl}-2$ prevents Bax-induced release of cytochrome $c$ and resultant secondary effects including megapore opening. At present, our studies have not distinguished between these two possibilities. While the precise site of Bax insertion into the mitochondrial membrane remains unknown, it may be physically occupied by Bcl-2. This possibility could explain our results using STP- and etoposide-treated HeLa cells.

Alternatively, Bcl-2 has been shown to interact with multiple proteins, while Bax is predominantly monomeric in non-stressed cells. ${ }^{16,24,25}$ The conformational change in Bax following the application of an apoptotic stress may reveal protein-binding sites necessary for its dimerization and insertion into the mitochondrial membrane. ${ }^{24,25}$ Such a hypothetical Bax-binding protein may be sequestered by $\mathrm{Bcl}-2$, thus preventing Bax translocation.

In addition to the mitochondria, $\mathrm{Bcl}-2$ localizes to the endoplasmic reticulum and nuclear membrane. ${ }^{28}$ Therefore, 
a third possible mechanism by which $\mathrm{Bcl}-2$ prevents Bax membrane translocation is by controlling an upstream event necessary for Bax insertion. All of these possibilities are currently under investigation. Regardless, our findings indicate that the mechanism is unlikely to involve Bcl-2/ Bax heterodimer formation because, at least in HeLa B-5 cells, Bcl-2 and Bax remained in separate subcellular compartments before, during, and after drug treatment (Figures $3 \mathrm{~A}$ and 5).

Throughout our studies of drug- and Fas-induced apoptosis of human cell lines, some of which have been stably transfected with $\mathrm{Bcl}-2$, we have observed a correlation between the extent of Bax membrane insertion and sensitivity of each cell line to apoptosis (this study and data not shown). This observation suggests that the cellular determinant of drug and Fas sensitivity is upstream of Bax membrane insertion. We and others ${ }^{38}$ have been unable to separate Bax mitochondrial translocation from cell death, suggesting that translocation of Bax is part of the execution machinery and may represent an irreversible commitment to cell death.

\section{Materials and Methods}

\section{Cell lines, drug treatments, and viability assays}

Human promyelocytic leukemia (HL-60) cells were grown in RPMI 1640 medium supplemented with $10 \%$ fetal bovine serum and $2 \mathrm{mM} \mathrm{L-}$ glutamine. The transfection, selection and growth conditions used for both control vector-transfected (S-1) and stable Bcl-2-expressing (B-5) HeLa clones used in this study have been described previously. ${ }^{30,31}$ Concentrated stocks of STP and etoposide were stored in DMSO at $-20^{\circ} \mathrm{C}$ and diluted immediately prior to use. Cells were exposed continuously to $1 \mu \mathrm{M} \mathrm{STP}$, or to etoposide (25 $\mu \mathrm{M}, 4 \mathrm{~h})$ following which they were washed twice with $37^{\circ} \mathrm{C}$ PBS and incubated in drug-free medium for the appropriate timepoints. Cell viability was estimated as the proportion of cells that excluded $0.2 \%$ trypan blue. ${ }^{30,31}$

\section{Subcellular fractionation}

For separation of subcellular cytosolic and nuclear/membrane fractions, 10 million cells were washed twice with ice-cold PBS and resuspended in $1 \mathrm{ml}$ of hypotonic lysis buffer (10 mM HEPES pH 7.4, $10 \mathrm{mM} \mathrm{NaCl}, 1 \mathrm{mM}$ phenylmethylsulfonyl fluoride, $1 \mu \mathrm{g} / \mathrm{ml}$ leupeptin, $1 \mu \mathrm{g} / \mathrm{ml}$ aprotinin) and incubated on ice for $30 \mathrm{~min}$. The cells were then disrupted by $6-7$ cycles of freezing in liquid nitrogen and thawing at $37^{\circ} \mathrm{C}$. After microscopic verification that $>95 \%$ of cells were lysed, the crude lysate was subjected to centrifugation at $100000 \times g$ for $1 \mathrm{~h}$ at $4^{\circ} \mathrm{C}$. The resultant supernatant, which consisted of the cytosol, was separated from the pellet, which represented the cellular membrane, organelle, and nuclear fractions. The pellet was resuspended in $1 \mathrm{ml}$ of hypotonic buffer. Equal volumes of cytosolic and membrane fractions were separated by SDS-polyacrylamide gel electrophoresis, transferred to polyvinylidene difluoride membrane and immunoblotted. The extent of cross contamination of each fraction was verified by measuring the activity of lactate dehydrogenase (a cytosolic marker), and immunoblotting for the nuclear protein topoisomerase I (topo I) and the mitochondrial protein cytochrome oxidase subunit VIc (COX). Experiments were only deemed valid if $>95 \%$ of the total lactate dehydrogenase activity was detected in the cytosolic fraction, and $100 \%$ of topo I and COX proteins were present in the membrane fraction.

\section{Immunoblotting procedures}

Immunoblotting was carried out as we have described previously ${ }^{31,42}$ using rabbit polyclonal antisera raised against human $\mathrm{Bcl}-2$ (amino acids 41-54), Bax (amino acids 43-61), caspase-3 (PharMingen) and actin (Sigma Chemical Company). In addition, mouse monoclonal antibodies against bovine PARP (clone C-2-10, Affinity Bioreagents, Inc.), bovine COX (clone 3G5-F7-G3, Molecular Probes, Inc.) and human topo I (clone C-21, kindly provided by Dr. Y-C Cheng, Yale University School of Medicine, New Haven, CT, USA) were used. Chemiluminescent signals were quantified using Hyperfilm MP (Amersham) which had been brought to the linear response range by preflashing to an OD540 of 0.15 . The intensity of each protein band was quantified using $\mathrm{NIH}$ Image software after scanning the image using a MicroTek ScanMaker III equipped with a transparency adapter. The proportion of individual proteins present in either the cytosolic or membrane fractions is expressed as a per cent of the combined total pixel density. Quantitative data are the mean of at least two separate experiments. PARP degradation was expressed as the percentage of the $M_{\mathrm{r}} 113000$ protein proteolyzed to the $M_{\mathrm{r}} 89000$ fragment. $^{6}$

\section{Caspase activity assays}

Cells were harvested, washed twice with ice-cold PBS, and lysed by six freeze/thaw cycles in $50 \mathrm{mM}$ PIPES pH 7.4, $50 \mathrm{mM} \mathrm{KCl}, 5 \mathrm{mM}$ $\mathrm{MgCl}_{2}, 5 \mathrm{mM}$ EGTA, $1 \mathrm{mM}$ PMSF, $10 \mu \mathrm{g} / \mathrm{ml}$ pepstatin A, $10 \mu \mathrm{g} / \mathrm{ml}$ leupeptin at a density of $10^{8} \mathrm{cell} / \mathrm{s} / \mathrm{ml}$. The lysate was centrifuged at $10000 \times g$ for $10 \mathrm{~min}$ at $4^{\circ} \mathrm{C}$ and the supernatant used to estimate caspase activity by cleaving the synthetic caspase- 3 substrate AcDEVD-pNA. The equivalent of $100 \mu \mathrm{g}$ of protein from cell lysates was pipetted into each well of a 96-well plate and $100 \mu \mathrm{l}$ of reaction buffer (20 mM PIPES pH 7.4, $100 \mathrm{mM} \mathrm{NaCl}, 10 \%$ sucrose, $0.1 \%$ CHAPS, $20 \mathrm{mM}$ 2-mercaptoethanol) containing peptide substrate (final concentration $100 \mu \mathrm{M}$ ) was added. Following a $1 \mathrm{~h}$ incubation at $37^{\circ} \mathrm{C}$ the absorbance at $405 \mathrm{~nm}$ (OD405) was subtracted from that in each well at zero time. Ac-DEVD-pNA cleavage activity was expressed as OD405/h/mg protein. Preliminary experiments had verified linearity of response over time and protein concentration (data not shown).

\section{Immunofluorescence}

Cells were grown on glass coverslips and drug treatments were carried out as described above. In some cases, cells were labeled with MitoTracker Red $\mathrm{CM}-\mathrm{H}_{2}$ XRos (Molecular Probes) for 45 min prior to drug treatment, and preliminary experiments had verified that the drug treatments used in this study did not alter the mitochondrial-specific MitoTracker Red staining pattern (data not shown). At the indicated timepoints cells were washed twice in PBS, fixed for $30 \mathrm{~min}$ with $3 \%$ formaldehyde in PBS, and permeabilized for 2 min with $0.2 \%$ Triton X100 in PBS. Non-specific binding was blocked by incubation with $5 \%$ BSA in PBS for $1 \mathrm{~h}$. Cells were then incubated with rabbit anti-Bax polyclonal antisera raised against a peptide corresponding to amino acids 1-21 of human Bax (06-499 Upstate Biotechnology), or mouse monoclonal anti-cytochrome $c$ (clone 6H2.B4, PharMingen) diluted $1: 50$ in $3 \% \mathrm{BSA} / \mathrm{PBS}$, for $1 \mathrm{~h}$ at $37^{\circ} \mathrm{C}$ in a humidified chamber. Excess antibody was removed by washing the coverslips four times with PBS. Cells were then incubated for $1 \mathrm{~h}$ protected from light with the secondary antibodies; FluoroLink Cy2 labeled goat anti-rabbit IgG and FluoroLink Cy3 labeled goat anti-mouse IgG (Amersham), diluted $1: 1000$ in $3 \%$ BSA/PBS. After washing four times with PBS coverslips were mounted onto microscope slides using ProLong Antifade mounting reagent (Molecular Probes). Control slides were stained 
with non-specific rabbit $\lg G$ or mouse $\lg _{1}$ (Sigma) and both secondary antibodies. Cells were viewed under a Zeiss Axioskop 20 fluorescence microscope and imaged using the Bio-Rad MRS 1024 Laser Scanning Confocal Imaging System.

\section{Acknowledgements}

Children's Cancer Institute Australia for Medical Research is affiliated with the University of New South Wales and Sydney Children's Hospital. This work was supported by RPG-98-063-CCE from the American Cancer Society, the Henry Vogt Cancer Research Institute and the Regional Cancer Center Corporation of the J. Graham Brown Cancer Center. KM Murphy is supported in part by a grant from the DEPSCoR initiative in Kentucky to Uldis N Streips. We thank Dr. Y-C Cheng (Yale University School of Medicine) for providing the topo I monoclonal antibody.

\section{References}

1. Thompson CB (1995) Apoptosis in the pathogenesis and treatment of disease. Science 267: $1456-1462$

2. Vaux DL and Strasser A (1996) The molecular biology of apoptosis. Proc. Natl. Acad. Sci. USA 93: 2239-2244

3. Kerr JFR, Wyllie AH and Currie AR (1972) Apoptosis: a basic biological phenomenon with wide-ranging implications in tissue kinetics. Br. J. Cancer 26: 239-257

4. Cohen GM (1997)Caspases: the executioners of apoptosis. Biochem.J. 326:116

5. Thornberry NA, Rano TA, Peterson EP, Rasper DM, Timkey T, Garcia-Calvo M, Houtzager VM, Nordstrom PA, Roy S, Vaillancourt JP, Chapman KT and Nicholson DW (1997) A combinatorial approach defines specificities of members of the caspase family and granzyme B. J. Biol. Chem. 272: 17907-17911

6. Nicholson DW, Ali A, Thornberry NA, Vaillancourt JP, Ding CK, Gallant M, Gareau Y, Griffin PR, Labelle M, Lazebnik YA, Munday NA, Raju SM, Smulson ME, Yamin T-T, Yu VL and Miller DK (1995) Identification and inhibition of the ICE/CED-3 protease necessary for mammalian apoptosis. Nature 376: $37-43$

7. Yang E and Korsmeyer SJ (1996) Molecular thanatopsis: a discourse on the BCL2 family and cell death. Blood 88: $386-401$

8. Kaufmann SH, Desnoyers S, Ottaviano Y, Davidson NE and Poirier GG (1993) Specific proteolytic cleavage of poly(ADP-ribose) polymerase: an early marker of chemotherapy-induced apoptosis. Cancer Res. 53: 3976-3985

9. Rosen A and Casciola-Rosen L (1997) Macromolecular substrates for the ICElike proteases during apoptosis. J. Cell Biochem. 64: 50-54.

10. Martin SJ and Green DR (1995) Protease activation during apoptosis: death by a thousand cuts? Cell 82: $349-352$

11. Li P, Nijhawan D, Budihardjo I, Srinivasula SM, Ahmad M, Alnemri ES and Wang X (1997) Cytochrome $c$ and dATP-dependent formation of Apaf-1/caspase- 9 complex initiates an apoptosis protease cascade. Cell 91: 479-489

12. Hakem R, Hakem A, Duncan GS, Henderson JT, Woo M, Soengas MS, Elia A, de la Pompa JL, Kagi D, Khoo W, Potter J, Yoshida R, Kaufman SA, Lowe SW, Penninger JM and Mak TW (1998) Differential requirement for caspase 9 in apoptotic pathways in vivo. Cell 94: 339-352

13. Kuida K, Haydar TF, Kuan C-Y, Gu Y, Taya C, Karasuyama H, Su MS-S, Rakic P and Flavell RA (1998) Reduced apoptosis and cytochrome c-mediated caspase activation in mice lacking caspase 9. Cell 94: $325-337$

14. Chao DT and Korsmeyer SJ (1998) BCL-2 family: regulators of cell death. Annu. Rev. Immunol. 16: 395-419

15. Kroemer G (1997) The proto-oncogene Bcl-2 and its role in regulating apoptosis. Nature Med. 3: 614-620

16. Reed JC (1997) Double identity for proteins of the Bcl-2 family. Nature 387: 773 776

17. Oltvai Z, Milliman C and Korsmeyer SJ (1993) Bcl-2 heterodimerizes in vivo with a conserved homolog, Bax, that accelerates programmed cell death. Cell 74 609-619

18. Green DR and Reed JC (1998) Mitochondria and apoptosis. Science 281: $1309-1312$
19. Susin ZA, Zamzami N, Castedo M, Hirsch T, Marchetti P, Macho A, Daugas E, Geuskens M and Kroemer G (1996) Bcl-2 inhibits the mitochondrial release of an apoptogenic protease. J. Exp. Med. 184: 1331-1341

20. Kluck RM, Bossy-Wetzel E, Green DR and Newmeyer DD (1997) The release of cytochrome c from mitochondria: a primary site for $\mathrm{Bcl}-2$ regulation of apoptosis. Science 275: $1132-1136$

21. Yang J, Liu X, Bhalla K, Kim CN, Ibrado AM, Cai J, Peng T-I, Jones DP and Wang $X$ (1997) Prevention of apoptosis by Bcl-2: release of cytochrome $\mathrm{c}$ from mitochondria blocked. Science 275: 1129-1132

22. LiF, Srinivasan A, Wang Y, Armstrong RC, TomaselliKJ and Fritz LC (1997) Cellspecific induction of apoptosis by microinjection of cytochrome c. J. Biol. Chem. 272: $30299-30305$

23. Rosse T, Olivier R, Monney L, Rager M, Conus S, Fellay I, Jansen B and Borner C (1998) Bcl-2 prolongs cell survival after Bax-induced release of cytochrome C. Nature 391: 496 - 499

24. Gross A, Jockel J, Wei MC and Korsmeyer SJ (1998) Enforced dimerization of $B A X$ results in its translocation, mitochondrial dysfunction and apoptosis. EMBO J. $17: 3878-3885$

25. Hsu Y-T and Youle RJ (1998) Bax in murine thymus is a soluble monomeric protein that displays differential detergent-induced conformations. J. Biol. Chem. 273: $10777-10783$

26. Wolter KG, Hsu YT, Smith CL, Nechushtan A, Xi X-G and Youle RJ (1997) Movement of Bax from the cytosol to mitochondria during apoptosis. J. Cell Biol. 139: $1281-1292$

27. Hsu YT, Wolter KG and Youle RJ (1997) Cytosol-to-membrane redistribution of Bax and Bcl-X(L) during apoptosis. Proc. Natl. Acad. Sci. USA 94: 3668-3672

28. Krajewski S, Tanaka S, Takayama S, Schibler MJ, Fenton Wand Reed JC (1993) Investigation of the subcellular distribution of the bcl-2 oncoprotein: residence in the nuclear envelope, endoplasmic reticulum, and outer mitochondrial membranes. Cancer Res. 53: 4701-4714

29. Jurgensmeier JM, Xie Z, Deveraux Q, Ellerby L, Bredesen L and Reed JC (1998) Bax directly induces release of cytochrome $\mathrm{c}$ from isolated mitochondria. Proc. Natl. Acad. Sci. USA 95: 4997-5002

30. Elliott MJ, Stribinskiene L and Lock RB (1998) Expression of Bcl-2 in human epithelial tumor (HeLa) cells enhances clonogenic survival following exposure to 5 -fluoro-2'-deoxyuridine or staurosporine, but not following exposure to etoposide or doxorubicin. Cancer Chemother. Pharmacol. 41: 457-463

31. LockRB and Stribinskiene L (1996) Dual modes of death induced by etoposide in human epithelial tumor cells allow Bcl-2 to inhibit apoptosis without affecting clonogenic survival. Cancer Res. 56: 4006-4012

32. Zhang H, Heim J and Meyhack B (1998) Redistribution of Bax from cytosol to membranes is induced by apoptotic stimuli and is an early step in the apoptotic pathway. Biochem. Biophys. Res. Comm. 251: 454-459

33. Goping IS, Gross A, Lavoie JN, Nguyen M, Jemmerson R, Roth K, Korsmeyer SJ and Shore GC (1998) Regulated targeting of Bax to mitochondria. J. Cell Biol. 143: $207-215$

34. Desagher S, Osen-Sand A, Nichols A, Eskes R, Montessuit S, Lauper S, Maundrell K, Antonsson B and Martinou J-C (1999) Bid-induced conformational change of $\mathrm{Bax}$ is responsible for mitochondrial cytochrome $\mathrm{c}$ release during apoptosis. J. Cell Biol. 144: $891-901$

35. Shibasaki F, Kondo E, Akagi T and McKeon F (1997) Suppression of signalling through transcription factor NF-AT by interactions between calcineurin and Bcl2. Nature 386: $728-731$

36. Marzo I, Brenner C, Zamzami N, Jurgensmeier JM, Susin SA, Vieira HLA, Prevost M-C, Xie Z, Matsuyama S, Reed JC and Kroemer G (1998) Bax and adenine nucleotide translocator cooperate in the mitochondrial control of apoptosis. Science 281: 2027-2031

37. Nechushtan A, Smith CL, Hsu Y-T and Youle RJ (1999) Conformation of the Bax C-terminus regulates subcellular location and cell death. EMBO J. 18: 23302341

38. Xiang J, Chao DT and Korsmeyer SJ (1996) BAX-induced cell death may not require interleukin $1 \beta$-converting enzyme-like proteases. Proc. Natl. Acad. Sci. USA 93: $14559-14563$

39. Murphy KM, Streips UN and Lock RB (1999) Bax membrane insertion during Fas(CD95) induced apoptosis precedes cytochrome c release and is inhibited by $\mathrm{Bcl}$-2. Oncogene In Press

40. Schlesinger PH, Gross A, Yin XM, Yamamoto K, Saito M, Waksman G and Korsmeyer SJ (1997) Comparison of the ion channel activity of pro-apoptotic BAX and anti-apoptotic BCL-2. Proc. Natl. Acad. Sci. USA 94: 11357-11362 
41. Bossy-WetzelE, NewmeyerDD and Green DR (1998) Mitochondrial cytochrome c release in apoptosis occurs upstream of DEVD-specific caspase activation and independently of mitochondrial transmembrane depolarization. EMBO J. 17: $37-49$
42. Lock RB (1992) Inhibition of p34 ${ }^{\text {cdc2 }}$ kinase activation, p34 ${ }^{\text {cdc2 }}$ tyrosine dephosphorylation, and mitotic progression in Chinese hamster ovary cells exposed to etoposide. Cancer Res. 52: 1817-1822 